\title{
ACCOUNTING FOR PLANETARY SURVIVAL ACKNOWLEDG: THE BACKGROUND
}

\author{
Michel Bauwens (org.) ${ }^{1}$ \\ P2P Foundation \\ michel@p2pfoundation.net
}

\begin{abstract}
The proposal of this paper is to present a summary of ten years of research at the P2P Foundation, including by our own P2P Lab but also by our partners in common research programs, of what we know today about the emerging commons economy. It includes a basic account of why the 'invention' of the blockchain has been important, but stresses that the needed distributed ledgers may take other forms in the future. This section may not offer a lot of new elements for those that are already technologically savvy about the topic, but it does offer a critical engagement with the qualities and flaws of the current model, and suggests how it can be tweaked and transformed, to also serve as a basis for a post-capitalist, commons-centric economy.
\end{abstract}

Keywords: 1. Emerging Commons Economy. 2. Blockchain Technology. 3. Planetary Survival.

\section{Resumo}

A proposta deste trabalho é apresentar um resumo de dez anos de pesquisa na Fundação P2P, inclusive por nosso próprio Laboratório P2P, mas também por nossos parceiros em programas de pesquisa comuns, sobre o que sabemos hoje sobre a economia emergente comum. Ele inclui uma descrição básica do motivo pelo qual a "invenção" do blockchain tem sido importante, mas enfatiza que os ledgers distribuídos necessários podem assumir outras formas no futuro. Esta seção pode não oferecer muitos elementos novos para aqueles que já são especialistas em tecnologia sobre o tópico, mas oferece um engajamento crítico com as qualidades e falhas do modelo atual, e sugere como ele pode ser ajustado e transformado, para também servir de base para uma economia pós-capitalista e economia centrada em bens comuns.

Palavras-chave: 1. Economia Emergente Comum. 2. Tecnologia de Cadeia de Dados. 3. Sobrevivência Planetária.

\footnotetext{
${ }^{1}$ Bibliotecário. Diretor e fundador da Fundação P2P. Ativista e pesquisador do Peer-to-Peer e do Commons.
}

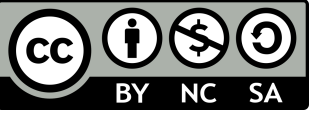




\section{Introduction}

\subsection{The P2P Foundation's study of the commons and the commons transition.}

When we started working as the P2P Foundation in 2006-2007, we started with a basic premise of what was wrong with the current political economy of capitalism. We claimed that the system combined strategies of artificial scarcity and pseudo-abundance in a way that increased social injustice and inequality.

The idea of pseudo abundance is based on the mistaken premise of infinite material growth on a finite planet, where natural resources are actually fundamentally limited. Artificial scarcity refers to the strategies that prevent the sharing of technological and scientific progress because of too restrictive intellectual property rights. A sensible alternative is, of course, to recognize the limits of what we can use from the world of nature, of which we are an intrinsic part, and to allow for the sharing of all knowledge that can contribute to living within the limits of this 'biocapacity'. Right now, we have a production system where competitiveness is achieved by externalizing human costs to nature and society as a whole. Capitalism has become a scarcity-engineering machine that prohibits the occurrence of natural abundance.

From this beginning, our theory of change was based on the idea that the seed forms of a new system grow within the old one, usually embedding an alternative logic to systemic crises.

We would point out that before capitalism became a fully dominant system, there were inventions like

- Double entry accounting which focuses on the rational expansion of private capital (Gleeson-White, 2013);

- Ideological innovations like the new Catholic concept of Purgatory ${ }^{2}$, which allow Christians to lend money, while buying back their sins through indulgences, and which allowed 'sinful' commercial activity (Legoff, 1981);

- The printing press, which allowed for the rapid production and distribution of knowledge, bypassing the knowledge monopolies of the Church and the guilds.

These new patterns and solutions, which created a proto-capitalist sub-system (dominant at first in the Italian cities and new medieval city-communes) (SPUFFORD, 2002),

\footnotetext{
${ }^{2}$ Purgatory can itself be interpreted as a karmic accounting system, an exchange system where money is exchange for the forgiveness of sins.
} 
were paradoxically first used by forces in the dominant feudal society, such as the monarchy, for their own ends. However due to this allegiance and investment the seeds of the new system were allowed to grow under the direction of the "capitalists" ${ }^{3}$ themselves. Seed forms emerge and slowly find each other to form more coherent subsystems- which eventually become the new dominant norm. This is not a smooth or conflict free process. Nevertheless, it is important to pay attention to the emerging forces rather than merely focussing only on the established power structures and conflicts. Today, this requires making a priority to analysing and supporting post-capitalist forms of human activity, rather than only pay attention to the fights for redistribution within the old system, or mere 'anti-capitalism' that is waiting for a 'final overthrow' of the system as a whole. These latter struggles remain an important part of reality, which must be honoured and understood, but are not creating the necessarily seed forms, though it is important that forces of resistance also become prefigurative in their demands ${ }^{4}$. What we propose is to construct seed forms that concretely solve social and environmental challenges, and a kind of politics that seeks to initiate policies that can replicate or scale such solutions.

According to De Angelis (2017), both the commons and social movements are enabling environments where individual emancipation takes place. They interrelate insofar as the commons provide alternatives, for which the social movements may strive. The process of social revolutions necessitates an alignment of commons with social movements, synchronizing their respective sequences "to turn the subjects of movements into commoners and make commoners protestors" (DE ANGELIS, 2017, p. 371). They thus become mutually reinforcing, through the expansion of the commons, which in turn forms a new basis for more powerful movements. Commons-Based Peer Production (CBPP) then serves as a driving force for the material recomposition of the commons. It enables the conditions to sustain livelihoods for the commoners and the deployment of social force to reconfigure their relations to the current social systems, including capital and the state.

We also claim that the emerging new world-system would be commons-centric, and that the existing state and capitalist market forms would be transformed under the new 'dominant' logic of the commons. What we saw emerging was a new mode of production and

\footnotetext{
${ }^{3}$ In this work, we use the concept of capitalism in a generic way, as a specific type of market system which separates commodified labor and ownership of capital and is geared towards the accumulation of privatelyowned capital. It includes the various forms such as industrial, financial, and cognitive capitalism. In the context of the commons we are especially interested in non-capitalist market forms, based on distributed ownership, in which capital is used for purposes other than its own accumulation.

${ }^{4} \mathrm{Cfr}$. Buckminster Fuller's often quoted line: "You never change things by fighting the existing reality.

To change something, build a new model that makes the existing model obsolete". Available at: https://www.goodreads.com/author/quotes/44478.R_Buckminster_Fuller.
} 
exchange, where communities create shared value through open contributory systems, govern their common work through participatory practices, and create shared resources that can, in turn, be used in new iterations. This cycle of open input, participatory process and commonsoriented output is a cycle of accumulation of the commons ${ }^{5}$, in contrast to a capital accumulation. This mode of production, which Benkler (2006), called "commons-based peer production", thrives in ecosystems comprising 1) contributory communities, sharing knowledge and capacities; 2) entrepreneurial coalitions creating livelihoods around the commons; and 3) for-benefit infrastructural organizations, which support and guarantee cooperation in the ecosystem, allowing it to continue over time.

Before this becomes a new form of civilization, it appears as new hybrid eco-systems in which post-capitalist seed forms exist within a framework dominated by the old forces. This understanding imposes a double priority on our work as activist researchers: first of all to document the emergence of these seed forms, as they are adapted and used by the current dominant forces, for their own survival and benefit, but also to look at how we can strengthen and create more autonomy for these commons-based productive communities. Our strategy is to identify, understand and promote the commons-centric, post-capitalist logics present in these emerging new forms. In the commons economy ${ }^{6}$ that we see emerging and want to strengthen, we see value created by open productive communities, translated into material resources for 'social reproduction' and livelihoods through ethical and generative enterprises, with the common infrastructures maintained by democratic foundations bringing the various stakeholders together in dialog, to jointly manage the common infrastructure.

A very important distinction for us is that between extractive and generative practices, and the institutional and ownership forms that enable it ${ }^{7}$ (KELLY, 2012). For example, every year a farmer practices industrial and toxic agriculture, the soil is impoverished, until it becomes exhausted for farming, but every year an organic and biodiverse farmer works on the land, the land enriches. The first mode is extractive, the second mode is generative from the point of view of the soil. Extractive are for example the companies in the most often mis-

\footnotetext{
${ }^{5}$ The 'Circulation of the Common' is an analytical concept proposed by Nick Dyer-Witheford in a landmark essay of the same title. It refers to the social reproduction mechanism of Peer Production, in a process analogous with the Circulation of Capital described by Marx. Available at: http://dlc.dlib.indiana.edu/dlc/bitstream/handle/10535/4519/circulation\%20of\%20the\%20common.pdf?sequence $=1 \&$ is Allowed $=\mathrm{y}$.

${ }^{6}$ See our report on value creation and distribution in a commons-centric economy: Value in the Commons. By Michel Bauwens and Vasilis Niaros. Heinrich Boll Foundation and P2P Foundation, 2016. Avaiable at: http://commonstransition.org/value-commons-economy.

${ }^{7}$ See also:

https://wiki.p2pfoundation.net/Emerging_Ownership_Revolution\#Characteristics_of_Generative_Ownership_Fo rms\%20for\%20further\%20details.
} 
named 'sharing' economy. While Uber and AirBNB scaled up the necessary mechanisms for 'idle-sourcing' (i.e. allowing the re-use of idle resources), they are socially extractive, destroying social welfare standards, creating precarity and insecurity etc. The key issue addressed in this study is how to change a system which incentivizes and rewards extraction and dispossession, but cannot recognize and reward the wealth created by generative activities, towards a system which can reward and incentivize generative practices. Furthermore, we are looking for generative practices that are embedded inside the productive system itself, and do not have to be imposed on it from the outside. Our current system is extractive towards nature and human beings and seeks for corrective measures 'after the fact'.

What we need are productive systems that are 'organically' or 'institutionally' generative.

Figure 1 - Value creation in the commons economy

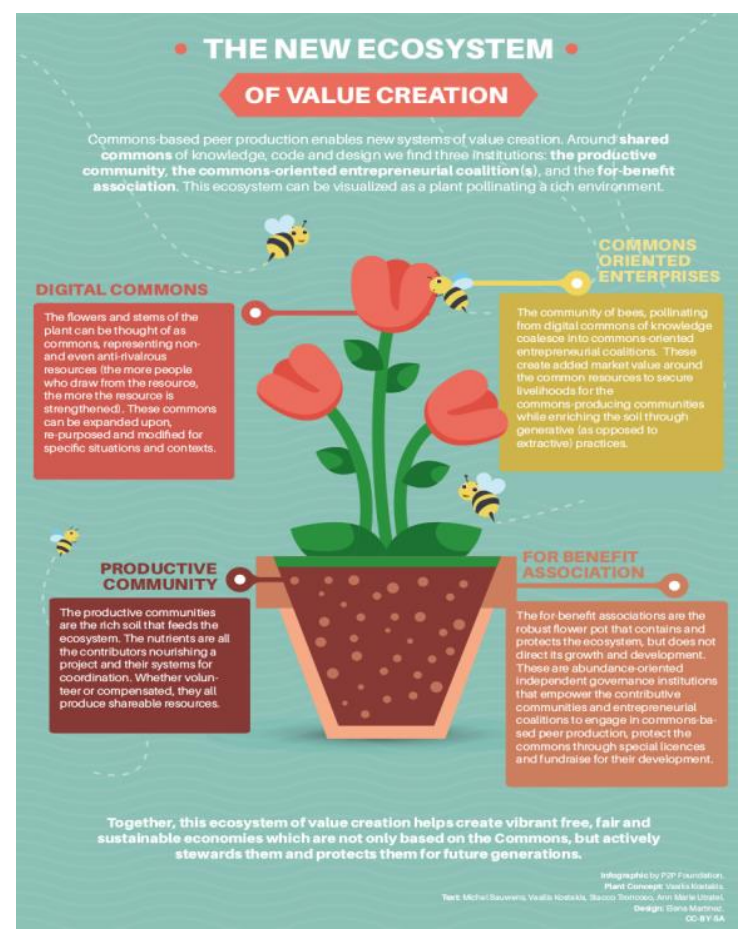

Source: P2P Foudation.

In today's context, we see on the one hand that the traditional, natural-resource based commons identified by Elinor Ostrom are under stress by the development of capitalism, while, on the other hand, we observe the growth of new types of commons. For example, we have seen the rapid emergence and growth of open source communities, co-producing shared knowledge, software and design. After the crisis of 2008, this was followed by the emergence of the platform economy, which brings supply and demand together in corporate owned 
platforms, but also the emergence of alternative platform cooperatives that are co-owned and/or co-governed by their stakeholder communities. And as the crisis was felt concretely in the cities where most people now live, we saw the emergence of urban commons, where commoners start taking the infrastructures for provisioning into their own hands. In our study of the city of Ghent ${ }^{8}$, we saw an exponential growth of urban commons, in every area of human provisioning, i.e. food, mobility, habitat etc. However, except for the sectors of organic food and distributed energy, which have highly developed ecosystems with commons-centric forms of organization, most of these urban commons pertain to a different distribution of the goods and services, not to the production of them. Nevertheless, the two latter examples point to a future where physical production itself could become commonscentric in its organization.

It is important to see what we are already capable of doing in terms of our techno-social capacities:

1. Open source communities are able to scale small-group dynamics by interconnecting tens of thousands of individuals and small groups, as well as larger groups, into large eco-systems for open coordination through 'stigmergy', i.e. coordination through signalling, by relying on open and transparent systems; the creation of shared knowledge (Wikipedia), shared software (Linux), and shared design (Arduino), already operates that way.

2. Platforms allow for the easy exchange of idle objects and services, using massive person-to-person interaction on a global basis.

3. Urban commons communities are able to organize access to resources that are more equitable and ecologically responsible.

The next step in the evolution of the ongoing transition to commons-centric ways of producing and distributing value is therefore 'physical production' itself. The central concept of the P2P Foundation in this context is 'cosmo-local production'9 or DGML ${ }^{10}$ : design global, manufacture local. This means that the technical, social and scientific knowledge needed to organize production is available through global open design communities, but that a large part of production for human needs can be relocalized through distributed manufacturing. What

\footnotetext{
${ }^{8}$ See our report: Changing Societies Through Urban Commons Transitions. By Michel Bauwens and Vasilis Niaros. P2P Foundation, 2017. Available at: http://commonstransition.org/changing-societies-through-urbancommons-transitions/.

${ }^{9}$ For a detailed treatment, see: http://wiki.p2pfoundation.net/Design_Global,_Manufacture_Local. KOSTAKIS et al. 2015.

${ }^{10}$ For a basic treatment, see: http://wiki.p2pfoundation.net/DGML.
} 
we favour is the subsidiarity ${ }^{11}$ of material production, i.e. to produce to minimize the huge costs of transportation currently necessary under neoliberal globalization. In this new model, 'economies of scale', i.e. bringing down the costs of production per unit by a massive scaling up of productive capacity through centralization, which necessitates ever more natural resources and transportation, are replaced by economies of scope ${ }^{12}$, i.e. making global knowledge and innovation instantly available to all nodes of the network, which can then apply circular economies, biodegradable materials, and more, to produce more directly for local need, as these needs emerge, without necessitating constant over-production and the constant promotion of over-consumption. With economies of scope, the object of production becomes, 'doing more with less', creating value through variety, rather than through volume.

Figure 2 - Cosmo-local production

\begin{tabular}{|l|l|l|l|}
\hline & $\begin{array}{l}\text { Traditional } \\
\text { manufacturing } \\
\text { enterprise }\end{array}$ & $\begin{array}{l}\text { Distributed } \\
\text { manufacturing } \\
\text { enterprise (neo-liberal } \\
\text { global factory) }\end{array}$ & Cosmo-localization \\
\hline $\begin{array}{l}\text { IP / knowledge } \\
\text { sharing regime }\end{array}$ & Held by one company & $\begin{array}{l}\text { Held by one company or } \\
\text { consortium (e.g. Apple) }\end{array}$ & $\begin{array}{l}\text { Shared under open or CC } \\
\text { or Peer Production license } \\
\text { etc. }\end{array}$ \\
\hline $\begin{array}{l}\text { Location of } \\
\text { manufacturing }\end{array}$ & $\begin{array}{l}\text { A single or local } \\
\text { manufacturing center }\end{array}$ & $\begin{array}{l}\text { Global factory, wherever } \\
\text { the product can be most } \\
\text { cheaply and effectively } \\
\text { produced, elements of } \\
\text { product can be produced }\end{array}$ & $\begin{array}{l}\text { Globally distributed } \\
\text { networks of localized } \\
\text { manufacturing, depending } \\
\text { on take up and use of } \\
\text { global design commons }\end{array}$ \\
\hline $\begin{array}{l}\text { Transport and } \\
\text { trade }\end{array}$ & $\begin{array}{l}\text { Product sent from local } \\
\text { manufacturing centers to } \\
\text { other places }\end{array}$ & $\begin{array}{l}\text { Parts move across many } \\
\text { countries and once } \\
\text { assembled are shipped for } \\
\text { trade }\end{array}$ & $\begin{array}{l}\text { Requires development of } \\
\text { localized production } \\
\text { ecosystems for complex } \\
\text { manufacturing, Micro- } \\
\text { manufacturing clusters }\end{array}$ \\
\hline $\begin{array}{l}\text { Enterprise } \\
\text { model }\end{array}$ & $\begin{array}{l}\text { Publically Listed Corp., } \\
\text { Family Owned Corp., } \\
\text { Nationalized Corp. }\end{array}$ & $\begin{array}{l}\text { Corporation or } \\
\text { consortium with complex } \\
\text { supply and distribution } \\
\text { ecosystem }\end{array}$ & $\begin{array}{l}\text { Open value network } \\
\text { model, }{ }^{3} \text { Platform } \\
\text { Cooperatives, Maker } \\
\text { Spaces, Phyles / Trans- } \\
\text { national collectives }\end{array}$ \\
\hline
\end{tabular}

Source: P2P Foundation.

The socio-technical requirements for this shift are essentially the following:

- We need open and shared supply chains to instantiate a perma-circular economy ${ }^{13}$, so that all the players in the ecosystem can plan and coordinate their production and

11 See the following citation: "Things are best done, in other words, at the smallest appropriate scale. Hence, Schumacher's vision wasn't that everything should be small and local, but that in all things, ranging from decision-making in firms, to growing and distributing food and generating energy, our default position should be toward human scale. In this, the distance between decision and consequence, production and consumption, is kept as short as usefully and practically possible. Every neighbourhood might, therefore, have its own bakery, but not a factory making trains". (http://www.guardian.co.uk/commentisfree/2011/nov/14/small-is-beautiful-efschumacher).

${ }^{12}$ For a basic treatment, see: https://wiki.p2pfoundation.net/Economy_of_Scope.

13 "The expression is a composite of "permaculture" and "circular economy". In a nutshell, I use it to designate a genuinely circular economy - one that not only insists on a generalized cyclical metabolism of the economy, but also on a culture of permanence: a deep questioning of the principle of economic growth. It's not an antigrowth concept per se. It merely follows common sense: What we need is selective and provisional growth of 
distribution activities. The circular economy refers to 'circular' production systems, where the output of one process, becomes the input for another, thereby drastically reducing waste. The 'perma' qualifier refers to the need to stabilize the growth of our usage of matter and energy so as to to make these processes sustainable over the long term. The limit to material growth has been calculated to be a maximally one percent per year ${ }^{14}$;

- We need shared accounting systems and distributed 'ecosystemic' ledgers, so that value streams can be exchanged. These systems need to allow permissionless contributions and need to reward these contributions in a fair way. Open and contributive accounting will be discussed in chapter $\mathrm{x}$;

- The open and shared accounting systems also need to reflect a integrated or 'holistic' knowledge of the actual 'metabolic streams', i.e. thermo-dynamic flows of matter and energy, and create a context-based sustainability for all the players in the ecosystem. What this means is that the limits to the usage of resources, should be directly visible in the ecosystems that create and distribute the particular product and service. Solutions for this will be discussed in our third chapter. As James Gien Wong explains: "Here we have the concept of localizing planetary boundaries down to a granular level. There should be thresholds that signal that a value exchange is coming close to exceeding a regional boundary. We need to have multi-scale setpoints that alert us that we are within acceptable ecological footprint boundaries".

The aim of this study is to offer an overview and synthesis of the seed forms that are emerging to make this a real possibility in the coming decades. The concepts, prototypes, experimentations and actual practices already exist, i.e. many of the seed forms have been developed, but they are as yet fragmented, and have not yet created generative ecosystems, with some exceptions.

The next step of creating such budding ecosystems requires paying attention to the technical systems being developed as we speak, for example the extraordinary developments around the deployment of distributed ledgers for shared accounting and coordination of production. The key issue that needs to be solved in order to achieve truly sustainable production for human needs, is whether what we produce is compatible with the survival of our planet and its beings. Equally necessary, is to pay attention to the value distribution. Indeed, most models developed today involve using open source and the commons to develop

those things that are valuable for ecological and human viability; what we don't need is the across-the-board and unlimited increase of all things deemed valuable by those who see technological and financial capital as the primary drivers of social progress". By Christian Arnsperger.

14 Xavier Rizos writes: "Francois Grosse, (former french engineer of Veolia) shows that circular economy cannot work above $1 \%$ growth, you merely differ the resource depletion of raw materials by maximum 60 years, but right now, most material use curves are actually 2-3\%, which means they are all following an Exponential Function. So even with recycling rates of $90 \%$ we have no solution for material depletion! So we need to limit growth, not of GDP which is a fairly meaningless metric, but directly related to the extraction of materials." Source: https://wiki.p2pfoundation.net/Thermodynamic_Efficiencies_of_Peer_Production. 
highly unequal extractive capitalist market forms, and do not use generative market forms that would help strengthen the autonomy of the commons and the commoners.

Technology is of course not neutral, since its design reflects human intentions, material interests, and a balance of power between developers, funders, users etc. We have a fourquadrant model to explain this value-driven design of technology.

Figure 3 - P2P socio-technical dynamics and cooperative forms: 2 pictures

\section{Picture 1}

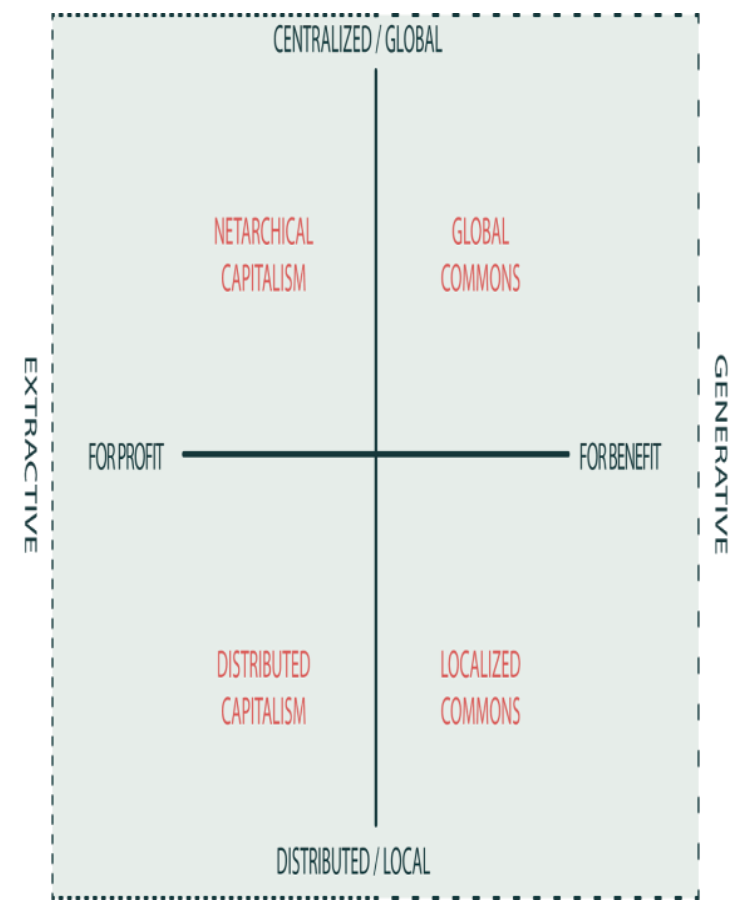

Picture 2

Summary of the Cooperative Forms for a Commons-centric Economy

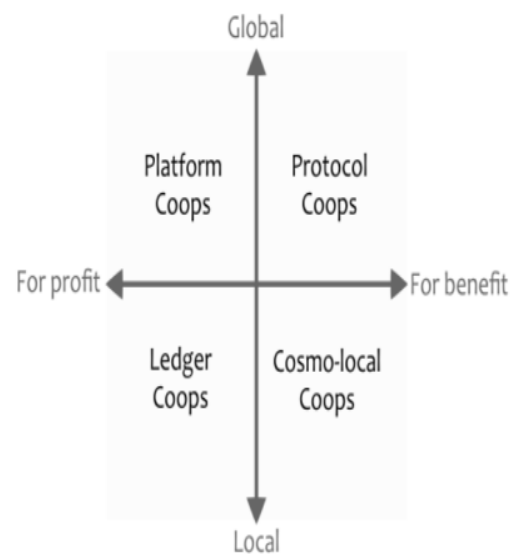

A first model involves enabling $\mathrm{p} 2 \mathrm{p}$ behaviours (both commoning and $\mathrm{p} 2 \mathrm{p}$-forms of market exchange) through centrally owned and controlled corporate platforms, think Facebook/Google, Uber/AirBNB as models for this. This model, which also includes state actors that aim to control internet communication and platforms, could be called Leviathan, since it is about surveillance, the control and nudging of human behaviour, and the capture of value from commoners.

The second model, which is the one that will be discussed mostly in this study, is the model of distributed capitalism. These are formally decentralized systems that aim to create permissionless usage by avoiding centralized gatekeepers (we will amend this over- 
simplification later on). We call this model Mammon ${ }^{15}$, as the aim is, despite the usage of open source technologies and commons of code, to extract profits.

The third model involves creating commons for local provisioning, this is the dominant model amongst urban commons, but that do not aim for profit-maximisation. Enzio Manzini has characterized these models as 'SLOC' ${ }^{16}$, for Small, Local, Open, and Connected. This model can share global knowledge over common platform, but still aim to operate locally, i.e the global serves the local.

Finally, there is a fourth model, based on global open design communities that aim to create global common goods and are organized beyond the local. In this model, the global is recognized as a priority in its own right. These projects are often managed by non-profit and democratically run foundations, but as yet to rarely surrounded by not-for-profit ${ }^{17}$ entrepreneurial coalitions.

For the third and fourth model, we often use the name of Gaia, the Greek Goddess of the Earth, since these projects are most often geared towards sustainability. The third model is specifically "generative" in its orientation towards local communities and ecological and social goals. In the fourth model, the ecosystems are generative towards the creation of global common goods that are universally available.

This means that we are not merely discussing competing models and platforms in the name of efficiency or profitability, but also worldviews, with different social and political priorities.

In the context of the P2P Foundation's own views, this means that we look at how to transform the functions of the central corporate platforms, into platform cooperatives ${ }^{18}$ and open cooperatives ${ }^{19}$ that do not merely capture the value created by their users, but can be coowned and co-governed by their stakeholder communities. In the case of the infrastructures of distributed capitalism, such as the blockchain, this means we will look how to tweak and

\footnotetext{
${ }^{15}$ The name is inspired by the Hebrew word for "money" and is described as a god of material things in the Bible, see: https://en.wikipedia.org/wiki/Mammon.

${ }^{16}$ Ezio Manzini writes: "the focus shifts from the wider, amorphous whole to the smaller specifics of a system designed for the human scale. Such systems, by their nature must be small, comprehensible and manageable. Once this is in place, they can then begin to connect with one another and interact with other similar smaller systems to reconstruct the whole. I call this complex relation between being small and open system, Cosmopolitan Localism." Ezio Manzini.

${ }^{17}$ In not-for-profits any profit is used to re-invest in the purpose and mission of the organization.

${ }^{18}$ This is a marketplace where the platform itself is cooperatively owned or managed by several stakeholders, instead of being a privately owned and often extractive business model.

${ }^{19}$ At the P2P Foundation, we consider coops to be one of the appropriate governance forms to manage shared resources; open cooperatives are coops that are institutionally committed to produce commons for the larger public.
} 
transform them, so they can be used to serve for the expansion of a socially equitable and ecologically regenerative model of production for human needs, serving the needs and interests of the commoners. In this context, we explore the concept of ledger coops ${ }^{20}$. The third quadrant calls for urban provisioning coops and in the fourth, generative global quadrant, we call for 'Protocol Cooperatives'. A protocol coop is basically a governance form for global open design depositories, collectively managed hubs of software to assist in the deployment of local systems for the mutualization of provisioning systems. In this scenario, leagues of cities could, with other allies, cooperate in the setting up of such common infrastructures, say in order to replace the extractive models of AirBnB, with generative models such as FairBnB, thereby avoiding duplication of effort. Please note that we use the concept of 'cooperative' in a generic way here, to indicate all institutional forms that are not geared towards profit-maximisation but to generative purposes.

Figure 4 - City-supported cosmo-local production infrastructure

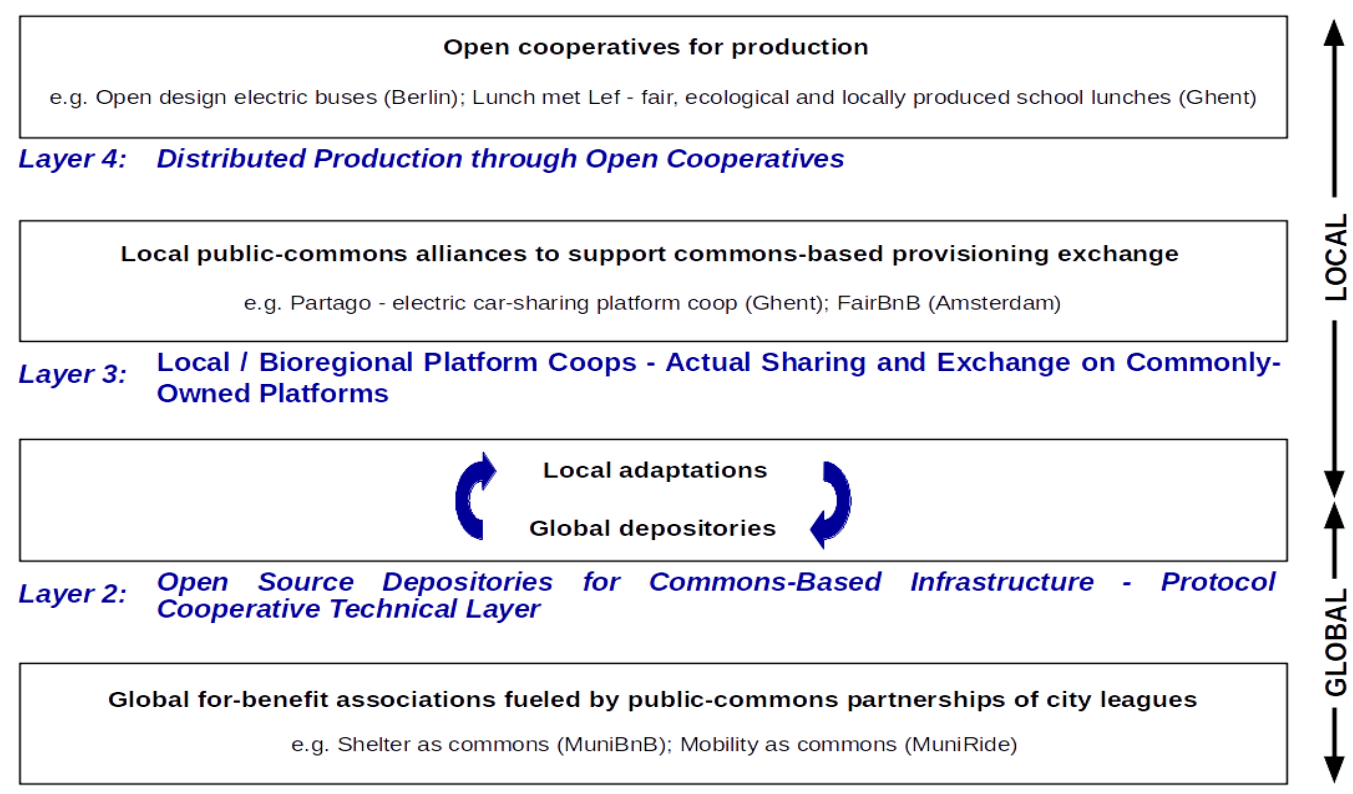

Layer 1: Institutional Layer-Protocol Cooperative Governance

The first law, of the conservation of matter and energy, states that no matter/energy can get lost, only transformed. This can be linked to the development of the idea of liberalism and the generalisation of support for growth-oriented capitalism, i.e. an economic system based on the idea of material abundance and infinite growth, since indeed, nothing can be lost.

\footnotetext{
${ }^{20}$ For example, we are exploring the concept of Distributed Income Support Cooperatives. https://wiki.p2pfoundation.net/Distributed_Income_Support_Cooperatives.
} 
The second law, on the dissipation of energy from high levels of order to lower levers of order, i.e. entropy, introduces the idea of scarcity, and a demand that basic needs should be covered, before they are unequally distributed. This new insight could be seen as reflected in the socialist aims of the labour movement.

But as Yochai Benkler (BENKLER, 2011), and others have described, there has been for the last few decades a much deeper appreciation of how human (and other forms of cooperation by living beings) cooperation and synergy leads to neg-entropic effects. This means that life and society create temporal and territorial exceptions to entropy and lead to domains where order and complexity increase over time. (Some have argued this should be construed as a third law. The new generations of technology should reflect this understanding and become eco-systemic and ecological in their approaches to producing and distributing value. This is only happening partially, in that our emerging systems apply are becoming ecosystemic but not yet truly ecological ${ }^{21}$.

The next two sections outline what we have discovered about value streams in the commons economy and introduce the issue of externalities.

Figure 5 - The three great spheres of social life in commons transition

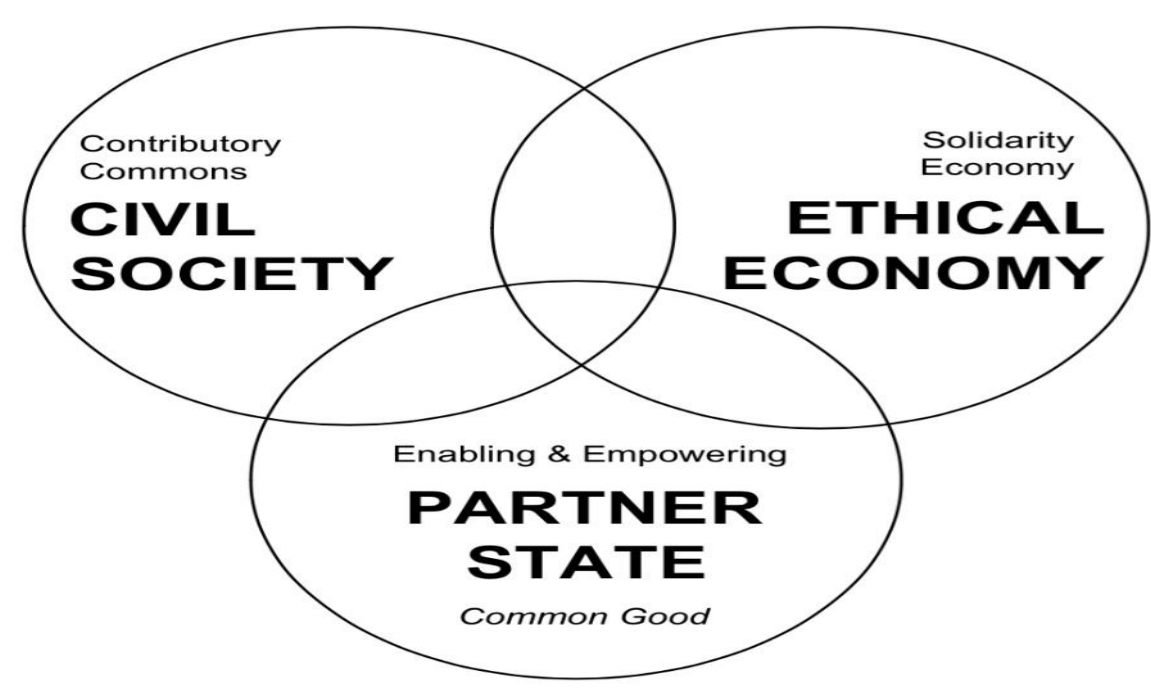

\footnotetext{
${ }^{21}$ There are various competing notions for this third law, which is scientifically still contentious. We are using James Quilligan's hypothesis because it makes the most sense in our specific context here.
} 


\section{Box 1- The evolution of the commons}

\section{The evolution of the commons}

We can use the following framework to 'historize' the evolution of the commons

1. The original commons are the natural resource commons, such as fishing grounds, irrigation systems, shared pastures, etc; these types of commons, still prevalent in parts of the global South, face enormous stress in the capitalist systems, which tend to privatize and enclose such commons.

2. Once the enclosures starts in Great Britain, and the common grounds are privatized, while the former farmers have to move to the cities for survival, the workers' movement ushered in an important emergence of social commons, in which 'life risk' is mutualized in mutual aid societies; many of these social commons will be nationalized to create social security systems.

3. October 1993 (the web and the browser) is the beginning of an exponential growth of networked knowledge commons with billions of people have access to such shared knowledge, which is also applied to cooperative production of free software and open design.

4. After the crisis of 2008, we see an exponential growth of urban commons for the re-organization of provisioning systems in the context of state and market failure, with food and energy already being self-produced by local commons-centric ecosystems.

5. Cosmo-local production occurs when collectives start moving to the production of material goods and services, whereby 'all that is light is global and shared, and all that is heavy is re-distributed and produced more locally.

6. The original commons are the natural resource commons, such as fishing grounds, irrigation systems, shared pastures, etc; these types of commons, still prevalent in parts of the global South, face enormous stress in the capitalist systems, which tend to privatize and enclose such commons.

7. Once the enclosures starts in Great Britain, and the common grounds are privatized, while the former farmers have to move to the cities for survival, the workers' movement ushered in an important emergence of social commons, in which 'life risk' is mutualized in mutual aid societies; many of these social commons will be nationalized to create social security systems.

8. October 1993 (the web and the browser) is the beginning of an exponential growth of networked knowledge commons with billions of people have access to such shared knowledge, which is also applied to cooperative production of free software and open design.

9. After the crisis of 2008 , we see an exponential growth of urban commons for the re-organization of provisioning systems in the context of state and market failure, with food and energy already being self-produced by local commons-centric ecosystems.

10. Cosmo-local production occurs when collectives start moving to the production of material goods and services, whereby 'all that is light is global and shared, and all that is heavy is re-distributed and produced more locally. 


\section{Box 2 - The evolution of research in the P2P Founation}

\section{The evolution of the commons}

The research base of the P2P Foundation started with a re-examination of the logic of transition periods, when one social or civilisation system is replaced by another. The key focus of the P2P Foundation is observing and understand seed forms that exemplify successor systems. We started by examining networked socialities and open source production communities, that are developing commons-centric forms of organization.

Based on our understanding of the logics if peer production, peer governance and peer property, we focused on the optimal relationships between the commons and the market, and the question of creating ethical livelihoods by tweaking and transforming market practice to allow the emergence of a commons-centric economy.

Then, we moved to public-commons cooperation and the commonification of public services, i.e. looking how cities, regions and state could relate to the emergence of these new forms of civic collaboration.

Once a grounded understanding of these 3 institutional realities and their mutual relations was in place, we started focusing on the enabling conditions, focusing on two main themes. I.e. the sustainability of material production (i.e. the thermodynamics of peer production), as well as new forms of human solidarity for the contributive economy in a networked age (commonfare).

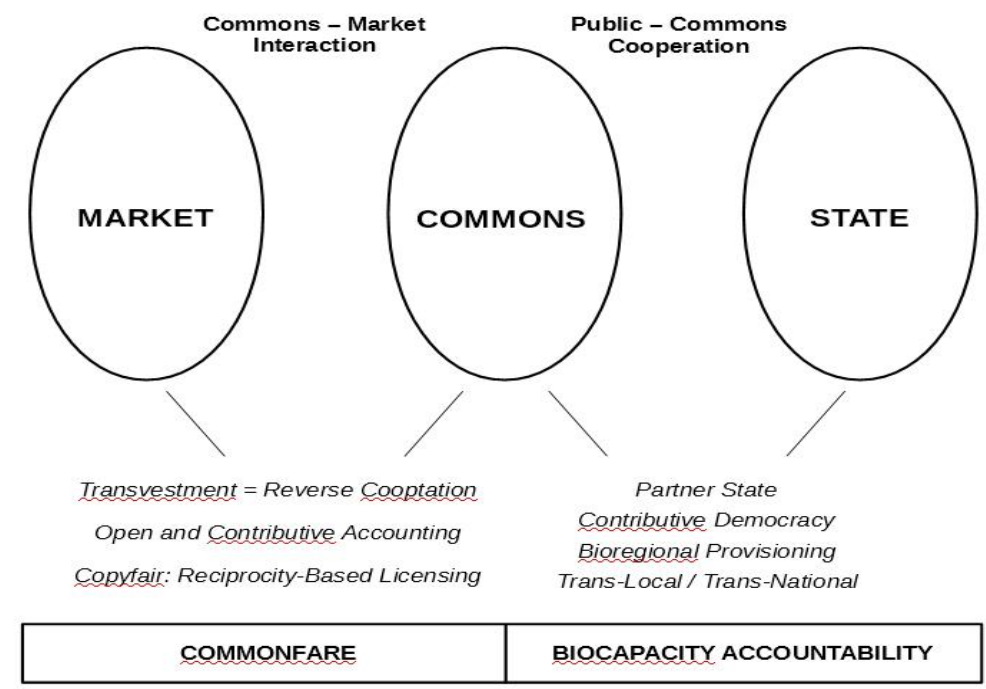

Source: https://wiki.p2pfoundation.net/images/Evolution_of_research.jpg.

\section{VALUE IN THE COMMONS.}

This report builds on the previous findings from earlier research reports. The P2P Value research project ${ }^{22}$ had shown that a majority of the 300 peer production projects that

\footnotetext{
${ }^{22}$ The P2P Value research project was undertaken by an EU-funded research consortium of which the P2P Foundation was a partner. It also concluded that contributors identified with their transnational contributory
} 
had been studied were engaged in using, prototyping or experimenting with contributive accounting, i.e. forms of accounting not based on hourly labor but recognizing all other manners of contributions in these open and permissionless production communities.

Our study, Value in the Commons Economy, based on different case studies of advanced peer production communities such as Enspiral and Sensorica, outlined the following concepts and practices:

- The new peer production communities are directly oriented to the production of use value, not exchange value, and make claims to 'value sovereignty', i.e. the right to determine context-based value regimes that differ from the sole recognition of commercial value under capitalism. This allows for a autonomous flow of value within the communities and for the recognition of all kinds of contributions, not just paid 'commodified labour'.

- These new communities create a membrane between the commons and the market, which allow them to regulate the flows of value between income from the market and state-based value models, and the internal flow within the commons, which can be differentiated from each other, in other words, it is possible to accept revenue from outside the commons, but to distribute according to the norms of a particular commons.

- We recognized three models: one in which the commons and the market are clearly demarcated, allowing free unpaid contributions and free usage within the commons, which is thereby protected against contamination by market exchange logics; a second model in which contributions are rewarded by a different value equation; which are then funded post-hoc by income from the market and the state; and finally a third one that more intimately and directly links commons contributions to market income.

- These communities practice and experiment with reverse cooptation of market income and investments, i.e. 'transvestment' ${ }^{23}$. While investment concerns using capital to obtain more capital, transvestment uses market and state investments, but translates them into the growth of commons assets and infrastructures. For example, capital is attracted and even remunerated, but increases the common stock of free software, or commonly-owned land in a land trust, etc. One of the techniques is to create a wall between investments and the purpose-driven generative entities creating livelihoods for the commoners.

- A few are experimenting with new forms of licensing, halfway between the 'free-forall' copyleft licenses and the privatizing copyright licensing models. In copyfair models, the sharing of knowledge remains entirely free, but commercialization is conditioned by some forms of required reciprocity with the commons.

community and that reputation functioned as a real capital good, opening access to resources. See: https://p2pvalue.eu/.

${ }^{23}$ For a detailed treatment of transvestment, see: here at https://wiki.p2pfoundation.net/Transvestment. 
A landmark study for us has been our research publication about the "Thermodynamics of Peer Production' ${ }^{24}$. In this study, we show the vital impact of mutualization of infrastructures of production and consumption, to the lowering of the footprint of humanity, which is already visible in the local commons-centric food economy for example. Sharing resources, for example in car-sharing that follows non-profit or cooperative modalities (but NOT using models like Uber, which augment resource use), every shared car can replace from 5 to 15 private cars ${ }^{25}$, dramatically reducing the needs for matter and energy expenditure.

This advantage were confirmed in our study of the urban commons in Ghent, where we were able to determine that, for every single provisioning system in the city, there are now no longer just choices between private and public models (say private housing vs state-sponsored social housing), but also commons-based alternatives (such as commons-based cooperative housing modalities). Various studies have confirmed, at least for car-sharing, that this type of mutualization effectively overcomes the Jevons Paradox, which states that lowering cost and efficiency often leads to higher consumption. Our challenge is to place the advantages of mutualization in lowering the human footprint in a sufficiently systemic change effort, so that gains in one sector are not undone by higher consumption in other sectors.

We cannot stress this enough: putting commons center stage, i.e. shared resources selfmanaged by their stakeholder communities, is a vital necessity in any social and ecological transition. This is confirmed by the HANDY study ${ }^{26}$, which compares the resource crisis moments of hundreds of past civilizations, starting from the neolithic period. Far from being exceptional, HANDY shows that civilizational collapses are a regular occurence in classbased societies, where ruling classes are perforce engaged in competition with their peers, and driven by this necessity, over-use their local resource base to the point of collapse.

The study shows that inequality is a vital part of accelerating and deepening such collapses: the more unequal the society, the more egregious the over-use, the deeper the fall, and the longer it takes to recover. Equality mitigates these crises and can perhaps even avoid them. Mark Whitaker ${ }^{27}$ has produced a comparative study of more recent collapses and resets

\footnotetext{
${ }^{24}$ See our report, Peer to Peer and the Commons: A matter, energy and thermodynamic perspective. (part I and II). By Céline Piques and Xavier Rizos with Michel Bauwens. P2P Foundation, 2016. Available at: https://commonstransition.org/peer-peer-commons-matter-energy-thermodynamic-perspective.

${ }^{25}$ For the sources for these figures, see https://www.transportenvironment.org/sites/te/files/publications/Doessharing-cars-really-reduce-car-use-June \%202017.pdf.

26 MOTESHARREI; RIVAS; KALNAY, 2014. Added discussion via https://wiki.p2pfoundation.net/HANDY_Model_for_Civilisational_Collapse_Scenarios.

${ }^{27}$ Ecological Revolution: The Political Origins of Environmental Degradation and the Environmental Origins of Axial Religions; China, Japan, Europe. by Mark D. Whitaker. Details and discussion via https://wiki.p2pfoundation.net/Political_Origins_of_Environmental_Degradation_and_the_Environmental_Origi ns_of_Axial_Religions.
} 
in China, Japan, and Europe, and has shown the vital role of mutualization in the revival of these societies. Notice the parallel between the role of pan-european exchange of knowledge by christian monastic communities, the mutualization of their production infrastructures in the monasteries, and the relocalization of production in the feudal domains, with the current emerging reactions: the creation of vast open source and open design communities, new forms of mutualizations of infrastructures in the models of coworking and makerspaces, as well as the 'sharing economy', and the increasing experimentation with cosmo-local models of distributed manufacturing.

An important part of any systemic change are changing class dynamics and structures within society. The shift from the Roman system, based on conquest and slavery, to the feudal system, based on local production in local territory, was a shift from slavery to serfdom and from slave-holding to feudal status. The shift from feudalism to capitalism was a shift from serfdom to working in factories. From land ownership to ownership of investment and financial capital.

In our analysis, the current shift involves a shift towards netarchical capitalism, i.e. the direct exploitation and capture of value, not from commodity labour in factories and offices, but from peer to peer exchange in platforms and from participating in commons-based peer production. In other words, the new capitalism is a commons-extracting capitalism, which directly enables, but also exploits, human cooperation ${ }^{28}$. One could say that we have evolved from a Marxian capitalism, with surplus value directly extracted from labour as a commodity, to a Proudhonian capitalism, since the latter argued that surplus value was derived from the extra value generated by human cooperation ${ }^{29}$.

In this particular conjuncture, we see the increasingly larger parts of the working class is evolving, at least in western countries, from a subordinate salariat to a condition of generalized precarity (some call it 'the precariat') (STANDING, 2011) ${ }^{30}$, but which also involves the growth of post-subordinate autonomous workers who are simultaneously involved in networks, commons, and markets ${ }^{31}$. These workers need to participate in networks to create connections, expertise and reputational capital, and are often passionately involved in contribution-based and permissionless digital commons; but they often operate as

\footnotetext{
${ }^{28}$ For a detailed description and analysis of these new, and poorly compensated 'digital labor' practices, see: EKIBIA; NARDI, 2017.

29 This 19th cy. Controversy is discussed in detail in: Commun: essai sur la revolution au XXIème siècle. Pierre Dardot and Christian Laval. La Decouverte, 2017.

${ }^{30}$ Excerpts via: http://goo.gl/Q8GcO.

31 We recommend the thoughtful treatment by Alex Foti, Alex Foti, General Theory of the Precariat. Source: http://networkcultures.org/blog/publication/general-theory-of-the-precariat.
} 
freelancers in the market. They often have a strong desire and demand for autonomy and free cooperation. In many ways, this 'cognitive working class' is at the forefront of social change today, becoming an active agent in the transformation in the system, largely thanks to their vital place in the knowledge ecosystem. This is evident in the growth of open source economies tied to the urban commons and other areas beyond what is usually perceived as "knowledge work". In this report we will concentrate on the growth of systems of production and distribution of value using distributed ledgers, or what is now known as the blockchain or crypto economy.

For the last year, one of the authors has been closely involved with a large European platform cooperative, SMart (coop), which is also called a labour mutual. In a labour mutual, formally independent workers, who in the best of cases have a passionate life project that allows them to filter their work engagements, are able to create solidarity, by converting their invoices into salaries, and thereby gaining access to the social protections of the welfare state.

These autonomous, post-subordinate workers also represent a convergence model between the precariat and the salariat, and are prime candidates for the emerging commons economy, they have a big role in the creation of the post-corporate eco-systems that we will be describing in one of the chapters of this report. Please note that we do not see these new types of workers as the sole actors in transformation, but we do believe they play a very important role in this particular transition. To the degree that the labouring classes start to see themselves not as merely adversarial to the current system, but as active commoners in the creation of new life forms, to that degree they are also joining the new commoner or 'hacker class $^{32}$.

\footnotetext{
32 "The hacker class is the class with the capacity to create not only new kinds of object and subject in the world, not only new kinds of property form in which they may be represented, but new kinds of relation beyond the property form. The formation of the hacker class as a class comes at just this moment when freedom from necessity and from class domination appears on the horizon as a possibility. Hackers must calculate their interests not as owners, but as producers." Sourced from an interview with the McKenzie Wark, at http://frontwheeldrive.com/mckenzie_wark.html.
} 
Box 3 - The role of labour mutuals, commonfare and post-subordinate workers

An increased number of workers, especially in Western countries, are either forced or choose to work more 'autonomously', considering work as a series of contributions or projects, but such a transition are often characterized by precarious living conditions. One of the ways to remedy this is through the creation of labour mutuals, through which workers start to mutualize their common work infrastructure, as well as to facilitate access to the social security services. One of the potential solutions is the model of a post-subordinate salariat, i.e. a model through which workers retain their freedom to choose or refuse projects, but yet join in a co-owned cooperative in which they are formally salaried, benefit from social security. In such a scheme, the various invoices of members are bundled to generate a regular salary, upon which taxes will be paid but in exchange for access to the services of the welfare state. Such a model is developed, for example, by the SMart cooperative (SMart.coop), which is active in nine different European countries.

\section{THE EMERGING CRYPTO ECONOMY AS A SIGNPOST FOR THE COSMO- LOCAL TRANSITION.}

If we look at the evolution of contemporary commons, from the emergence of the immaterial 'digital' commons for knowledge, software and design, via the mostly redistributive provisioning systems of the urban commons, we now see the emergence of a new phase that involves bringing the use of the open source and commons models, straight into the physical production processes. For example, the Economic Space Agency speaks of a shift from open source software production methodologies, to open source economic spaces, i.e. from the mere production of knowledge, code and design, to full-scale economic cooperation around the production and distribution of all kinds of value, so as to secure livelihoods.

The emergence of the distributed Bitcoin currency, and most importantly its underlying infrastructure broadly discussed as blockchain technology, is a very important signpost for this, as we explain further in this document. In this chapter, we aim to provide a short explanation of this emergence, critique the current models from a P2P and commons-based point of view, so that we can suggest the main tweaks and transformations that are necessary for the support of a true, solidly commons-oriented mode of production and exchange in the sphere of physical production. This would combine our priorities for open and freely shared 
knowledge, respect for the biocapacity of the planet, and fair distribution of the rewards for common work.

The aim of this work is to see how we can 'internalize' in our management of the production and distribution of value what is presently 'externalized', i.e. not accounted for and not cared for.

The design, emergence and success of Bitcoin was a very important first pivot. Over the last decade there has been an increasing number ${ }^{33}$ of locally based complementary currencies, but with limited numbers of local users and turnover. To date, they very rarely achieve scale even in their local contexts ${ }^{34}$. By contrast, Bitcoin was the first attempt for a globally scalable currency that was based on social sovereignty, instead of corporate or statebased sovereignty.

The trust of the community was ensured, not by mediating third party institutions but by trust in the integrity of cryptographic rules. For the first time in recent history, we have a currency that was created autonomously, and gained the trust of a global community, while achieving tangible and spectacularly recognized levels of market value. Following Bitcoin, many other cryptocurrencies are also achieving relative success, even amid the speculative frenzy. We can observe a surge of permissionless creation of currencies, with a relatively autonomous capacity to allow value flow outside of the traditional banking channels, which gave rise to the idea of crypto-assets. These value flows are coordinated in more decentralized ways, even if new types of intermediaries may be facilitating this. Cryptocurrencies have thus been envisioned as a store of value, and a kind of global reserve backing, like gold, but their usability in day-to-day exchanges in real marketplaces has not been realized, except very marginally. At any rate, crypto-currencies introduce the idea of pluralist value streams and the circulation of assets in decentralized P2P networks.

However, even if the Bitcoin code is open source and supported by a global community, there are also huge issues that do not make it an appropriate currency for the commons economy. Essentially, the commons are subsumed here to social and ecological extraction. Social extraction, because the particular design means that early entrants can sell bitcoins at a higher price later (because production is designed to slow down and even stop over time, while demand grows without set limits, thereby structurally stimulating demand

\footnotetext{
${ }^{33}$ According to LIETAER; KENNEDY (2007 apud BENSCHA, 2016), there are currently 6,000 to 7,000 of various types of local currencies, Source: https://payment21.com/blog/complementary-currencies-enteringdigital-era.

${ }^{34}$ New measurement techniques may be able to change this general appreciation, see the efforts of Grassroots Economics in Kenya and other African countries. See: https://www.grassrootseconomics.org/singlepost/2018/12/13/Proof-of-Impact.
} 
over supply ${ }^{35}$ ) and this has made bitcoin into a tool for financial speculation ${ }^{36}$. And ecological extraction, since its production necessitates exponential energy usage ${ }^{37}$.

Value in Bitcoin is created through the monetary mechanism itself, not by the creation of productive value. In fact, Bitcoins are created through an extremely resourceintensive process called "mining", which is very capital and resource intensive, as it requires huge computational capacity. Bitcoin thus relies essentially on capitalist mechanisms for its existence. Furthermore, almost the entirety of Bitcoin mining has gradually been taken over by vast mining plants, specially designed to afford enormous processing power, making it almost impossible for single users to engage in any mining themselves ${ }^{38}$. Hence, Bitcoins for them can only be acquired in exchanges, again via the capitalist market (or by working for the owners).

Most cryptocurrencies are traded as financial assets on open markets, i.e. their price is based on supply and demand, and is denominated in regular fiat currency. Value flows from one currency into another, but the currency is a representation, that does not create value by itself any more than a balloon creates 'volume'. In other words, Bitcoin owners extract rent from productive value creators in the rest of the economy, it is a distribution of rent-seeking ${ }^{39}$. Bitcoin is most certainly a currency of and for the market, more specifically a currency for decentralized capitalist market dynamics, specifically for market forms that seek to escape governmental and societal control.

Beyond Bitcoin and other cryptocurrencies, a second generation of blockchains introduced autonomously executed computer processes broadly known as "smart contracts". These are software programmes stored on a blockchain and employ a set of pre-defined rules that may be enforced automatically once certain conditions are met. Multiple parties in a

\footnotetext{
35 Dan Kervick describes the problematic deflationary design as a scheme for extraction here at: http://neweconomicperspectives.org/2013/04/talking-bitcoin.html.

${ }^{36} \mathrm{We}$ agree with the evaluation of James Gien Wong: “in hindsight, it was natural that it emerged at the intersection of distributed computing networks and capitalism, but from the commons perspective, it is at the very bleeding edge. It's importance to the commons is that it proved that there is a global appetite for it, but it still shares fundamental DNA with the traditional form of extractive capitalism that birthed it. Now the job is to replace extractive distributed value exchange with a more equitable form". From a comment to our draft report.

${ }^{37}$ See in particular: https://arstechnica.com/tech-policy/2017/12/bitcoins-insane-energy-consumption-explained/; For various additional statistics on its energy usage, see: https://wiki.p2pfoundation.net/Bitcoin\#Energy_Usage_Aspects.

38 There are mining pools (https://bitcointalk.org/index.php?topic=1975844.0), and cloud mining services (https://hashflare.io/), (the latter considered problematic by many in the crypto community), that allow for individuals and groups to do their own mining.

${ }^{39}$ This discussion is separate from any recognition that a cryptocurrency network has a 'value in itself' as a new form of infrastructure. Philip Honigman argued in a comment on our draft: "irrational speculation asides, which certainly plays a role, there is a value intrinsic to decentralized autonomous money - and the cost to produce it, as excessive it might seem today, is an inherent requirement to its production".
} 
distributed network can access and interact with smart contracts, but they are largely autonomous and very difficult to reverse once deployed.

Ethereum was the first initiative supporting the deployment of smart contracts on a blockchain. It envisioned a potential use of blockchains that goes beyond the storage or reference of transactions, but may include any type of information that allows users to define the functionality of decentralized applications (dapps). Ethereum also implements its native crypto-currency called "Ether" that, much like Bitcoin, is allocated to miners through a similar process and can be transferred in the network.

Smart contracts gave rise to an ever-increasing number of potential uses of blockchains, on every domain where formal agreements have to be encoded and enacted, including financial transactions, insurance and securities, and intellectual property rules. Probably the most ambitious deployment of smart contracts has been new types of decentralised organisations, commonly referred as "Decentralized Autonomous Organizations" (DAOs), which rely purely on blockchain code and the distribution of tokens to enforce their rules to control decision making and operations. The DAOs have stimulated discussions and experiments around the provisioning of digital services and transactions that take place with little or no direct human action, while they arguably cede agency to nonhuman subjects, including machines, objects or even natural ecosystems.

It is especially in this light that the blockchain, or more broadly 'Distributed Ledger Technology' (DLT) has been acknowledged as an even more radical innovation. We note that accounting and civilization have developed together. Writing was invented as a by-product of accounting, when temple-state, class-based civilizations emerged in Mesopotamia, to keep track of the coming and going of commodities in the temple storage paces, as well to record debts. These first forms of accounting accompanied the birth of class-based civilization and the accompanying state forms. When the Franciscan monk Pacioli standardized 'double entry' Venetian bookkeeping in the year $1494^{40}$, it announced the birth of capital accumulation which would eventually engulf the whole world a few centuries later. Today, next-generation accounting models, such as Resources - Events ${ }^{41}$ - Agents abandon double-entry to favor ecosystem- and network-based accounting flows. What we get is something that goes beyond closed corporate accounting and potentially announces and accompanies a huge civilizational

\footnotetext{
${ }^{40}$ Luca Pacioli's "Summa de arithmetica, geometria, proportioni et proportionalita" (1494, Venice: Paganino di Paganini) is regarded to be the first known printed treatise on double-entry bookkeeping. For more details see: SANGSTER, 2010.

${ }^{41}$ REA accounting is explained in chapter 3. It is an accounting solution for entities and individuals working in a networked ecosystem, and situates every transaction in the flow of all actors of that system.
} 
shift away from atomized institutions that compete with each other, and instead points towards a more networked structure based on much higher levels of collaboration over joint platforms.

The blockchain encodes and shows the viability of open and shared accounting in representing the multitude of transactions and actions occurring during physical production. This is historic, as this allows us to move from corporate and nation-state accounting, (which even as they are publicly regulated and accessible to the public, are 'privative' accounting internal to bounded entities, in which externalities are invisible), to ecosystemic accounting in networks with multiple participants and in an environment of permissionless contributions. In other words, it allows for large-scale mutual coordination of physical production, and makes practical the scaling of circular economies. It is an extension of the principles of the open source economy, to physical production.

Distributed ledgers furthermore allow both the recognition of a variety of contributions, i.e. open and contributive accounting, but also the capacity to integrate directly the visioning and management of physical flows of matter and energy ${ }^{42}$. This differs from the previous approaches such as Ecological Economics, that converted resources in price signals $^{43}$. The combination of distributed and shared ledgers, as well as the capacity to integrate externalities, constitute a radical innovation

Presently, the production of immaterial value, i.e. knowledge, software and design, enables 'stigmergic coordination' 44 between permissionless contributors, who can access open and transparent depositories that represent the flow of work. With shared accounting, this capacity for mutual coordination moves to the physical plane. But because physical production requires specific reciprocity in terms of material capital (which otherwise would get depleted), and not just the principle of free universal usage, it requires that distributed ledgers add this layer of value exchange.

To use the 19th century language, for example as used by Marx:

- As far as immaterial production is concerned, we already have the principle of 'communism' at work in the very heart of the capitalist economy (in its original sense of 'everyone can freely contribute and everyone can freely use'), which some authors like Richard Barbrook have called cyber-communism (or 'cybernetic communism', BARBROOK, $2015^{45}$ ), because of the 'abundance' of digital knowledge which is easily and cheaply reproducible, and thereby overwhelms the scarcity dynamics of supply and demand, moving the market functions to the periphery of open source

\footnotetext{
${ }^{42} \mathrm{As}$ an example, see footprint analysis, see: https://data.footprintnetwork.org/\#/exploreData.

${ }^{43}$ For example, see: https://en.wikipedia.org/wiki/Ecosystem_valuation\#History_and_Economic_Model.

${ }^{44}$ For details about stigmergic coordination, see: https://wiki.p2pfoundation.net/Stigmergy.

45 According BARBROOK, 2000.
} 
production communities, with the commons in the middle. Paradoxically, this cooperative coordination is largely incorporated in the corporate economy, inspiring some scholars to speak of the 'communism of capital' (BAUWENS; KOSTAKIS, 2014).

- In physical production however, we need reciprocal flows, to avoid depletion of nonrenewable resources, either through market exchange (but not necessarily capitalist exchange) or through contributory recognition ('to each according to his/her contribution', this was defined by Marx as 'socialism,46). Capitalist markets are nominally based on the idea of equal exchange, but in their actual practice they are based on the constant extraction of surplus, from nature and other humans, in order to accumulate capital in private hands.

Ethical and generative markets use monetary signals, but are not focused on profit maximisation. Many pre-capitalist markets were socially embedded, as Karl Polanyi has shown. We will later show that we need to move from pricing signals, which reflect current supply and demand, but not the necessities of protecting and maintaining resources in the long term, to monetary signals, i.e. to currencies that are directly related to the status of the natural resources we need to maintain and replenish ${ }^{47}$. If such a linkage between the amount of natural reserves that are sustainably available, and a corresponding monetary mass could be achieved then the monetary signals themselves would be a technique for responsible material production $^{48}$. An example of this is the Fishcoin project, in which the amount of coins that can be spent reflect the stock of fish that can be used without endangering the reproduction of the fish.

So, the blockchain, like Bitcoin, has received extensive attention and a huge wave of investments, viewing it as a new infrastructure layer for a more distributed economy. And precisely because it is linked to the design philosophy of Bitcoin, it shares some of its fundamental limitations. The design of Bitcoin and its infrastructure are based on an individualistic understanding of the economy, that combines elements from the marginalist traditions, Austrian Economics' and an 'anarcho-capitalist', 'propertarian' philosophy. It is

\footnotetext{
${ }^{46}$ See this article for the distinctions: https://j-humansciences.com/ojs/index.php/IJHS/article/view/3152.

${ }^{47}$ An early proosal was the Terra, a global complementary currency designed to provide an inflation-resistant international standard of value; to stabilize the business cycle on a global level; and to realign stockholder's interests with long-term sustainability. See: http://www.lietaer.com/2010/01/terra/.

${ }^{48}$ Charles Eisenstein presents a proposal for this in Sacred Economics: "Once we have decided how much of each commons should be made available for use, we can issue money "backed" by it. For example, we might decide that the atmosphere can sustain total sulfur dioxide emissions of two million tons a year. We can then use the emissions rights as a currency backing. The same goes for the rest of the commons. The result would be a long list comprising all the elements of the commons we agree to use for economic purposes". See here for full context: http://sacred-economics.com/sacred-economics-chapter-11-currencies-of-the-commons/.
} 
based on 'methodological individualism ${ }^{49}$ ', the premise that society consists of individuals seeking maximum advantages in a competitive game. Every human being is seen as an entrepreneur, which contracts with others in order to conduct his or her business.

For example, when blockchain projects talk about governance and 'consensus', what they emphatically don't mean is collective governance based on democratic deliberation, but merely the coordination of individual actions with common intentions ${ }^{50}$. Because liberalism believes that the common good results from individual and corporate competition, it has no clear concept to articulate it other than the accumulation of individual gains, and it does not see the inter-dependence of the market to a whole host of societal and environmental realities. The commons and open source dynamics are often appropriated to emphasize individual freedom, mostly restrained to a 'one dollar, one vote' context, disregarding the elements of social fairness and ecological sustainability.

As Arthur Brock has argued, there are no people and communities in the blockchain design, no community governance, 'only transactions organized in blocks linked to a chain' ${ }^{51}$; there is no organic connection between the blockchain and the open source communities and commons that undergird it ${ }^{52}$.

Furthermore, bitcoin and blockchain are not truly distributed, i.e. consisting of equipotent peers that voluntarily create nodes through their free and open cooperation, but rather decentralized. This means that while it avoids the domination by vertically integrated oligarchic companies, it is still based on major power blocks, such as influential 'miners',

\footnotetext{
${ }^{49}$ Rachel O'Dwyer writes: "What kinds of subjectivity do we want to algorithmically inscribe into our systems? Blockchain start-ups begin from the assumption that there is no trust and no community, only individual economic agents acting in self-interest. Fair enough, you might think, it's precisely the fact that projects like Ethereum engineer confidence and provide economic incentives for contribution that may distinguish it from other services like Freenet. But it also proceeds from a perspective that already presumes a neoliberal subject and an economic mode of governance in the face of social and/or political problems. 'How do we manage and incentivise individual competitive economic agents?' In doing so, it not only codes for that subject, we might argue that it also reproduces that subject". Source: https://www.academia.edu/11627298/The_Revolution_Will_not_be_Decentralised_Blockchainbased_Technologies_and_the_Commons.

${ }^{50}$ Even more narrower is that consensus is a technical term describing how different nodes agree on which block to publish next. This article is part of a series on consensus and governance and is illustrative of the kinds of debates: https://blog.coinfund.io/the-consensus-series-part-i-the-basics-of-collectivity-a11d76ff4d5d.

${ }^{51}$ Arthur Brock writes: "In computer science, an ontology describes what EXISTS in a system. For example, In Bitcoin what exists are transactions organized into blocks linked in a chain. The first transaction in each block gets to create new coins (cryptographic tokens). The other transactions spend a coin by signing (with a private key) the previous transaction to a new owner (using their public key as their address/identity). There are also nodes with which you send and receive transactions. Notice no people in that ontology. They don't exist. With no people, there are no relationships, no communication, no interconnection, and no community. How can a community that doesn't exist regulate itself?" Cited from: https://medium.com/metacurrencyproject/cryptocurrencies-are-dead-d4223154d783.

52 This is why, by contrast, Holochain is entirely 'agent-centric', i.e. designed around people.
} 
large investors, etc. Bitcoin's inequality coefficient ${ }^{53}$, measured by the Gini metric, is higher than the inequality in the sovereign currencies that it aims to replace. Blockchain has an oligarchic design ${ }^{54}$, as most mechanisms used to reward contributions (the 'proof of work' mechanism) and resources (the 'proof of stake' mechanism), reward those that can already provide the most.

Sam Pospischil writes ${ }^{55}$ :

$[\ldots]$ blockchains are too slow and expensive for a large variety of use-cases. If you look at something like, say, OriginTrail, they've built a separate overlay network to store structured graph data and document attachments. Pretty much everyone has something similar, with varying levels of "decentralised-ness" ranging from traditional SQL databases to networks that anyone can spin up and participate in just like a (public) blockchain.

Different layers of the blockchain ecosystem are routinely dominated by a small group of dominant players, even if they have to content with the other layers in the system, miners, developers, users.

What matters in this report therefore, is not necessarily the blockchain in the narrow sense, but the generic concept of distributed ledgers ${ }^{56}$. Nevertheless, it would be a mistake to underestimate the innovative features of the blockchain design, which Sarah Manski has summarized.

\footnotetext{
53 We have collated various figures about the unequal distribution of Bitcoin, here at https://wiki.p2pfoundation.net/Bitcoin\#Bitcoin_inequality_statistics. For the Gini statistic. See: Gini Coefficient $=0.87709$; Bitcoin Wealth Distribution extremely unequal (Bitcoinica data), the $1 \%$ own 50\%; see more at http://ow.ly/trKoy.

${ }^{54}$ If someone tells you they're building a "decentralized" system, and it runs a consensus algorithm configured to give the people with wealth or power more wealth and power, you may as well call bullshit and walk away". Sourced from Arthur Brock at https://medium.com/holochain/blockchain-blind-spots-1904d490218d.

${ }_{55}^{5}$ This is copied from an email conversation with one of the authors.

${ }^{56}$ Please note that these collaborative or interoperable ledgers need not be tamper-proof. As noted in a comment by Marco Fioretti: "In some cases, namely food, delivering what promised may cause LOTS of extra pollution and consumption of raw materials. In addition, it may even destroy small producers, making informal/grey economy impossible, if it happens without simultaneous deep changes in tax and other regulations."
} 


\section{Box 4 - The seven tendencies of blockchain technology by Sarah Manski}

\section{Seven tendencies of blockchain technology and the structural qualities that produce them}

1. Verifiability Transactions are assured through encrypted network consensus mechanisms in such a form that all transactions from the very first to the most recent are recorded in a ledger open to its maintainers, reducing information asymmetries

2. Globality Digital transactions and cultural information flows transcend geographic space and national borders

3. Liquidity Value liquidity is enhanced as the location of a store of value that does not depend or is not under the direct control of a sovereign, central bank or private corporation

4. Permanence The ledger of transaction is immutable by design

5. Ethereality Transactions are conducted in a digital medium

6. Decentralization The ledger is widely distributed among many stakeholders and maintainers

7. Future Focus Found in newer developments of blockchain such as Ethereum, a stored autonomous self-reinforcing agency (SASRA) is formed in the temporal displacement of action through the use of smart contracts enabling the prefigurative recording of future transactions

Sarah Manski has also analyzed the underlying political visions of the blockchain designs, resulting in five possible futures ${ }^{57}$ :

- The first is the individualist future, based on anarcho-capitalist visions of the world, in which every individual is seen as a competitive entrepreneur;

- the second is the corporate vision, which can use ledgers for a variety of for-profit and procontrol-base uses;

- the third is the vision of particular state forms with a desire for control and surveillance,

- the fourth is the technocratic future, expressing the fear that such technologies can become automatic and sovereign, beyond human control.

- $\quad$ But the fifth one is the cooperative future, in which distributed ledgers are used for the commons. This is the vision that animates this report.

Rachel O’Dwyer also provides an extra warning: if we design distributed ledgers following the values and processes of 'methodological individualism', then we also end up generalizing and socially reproducing these neoliberal mechanisms ${ }^{58}$. As Salvatore Iaconesi

\footnotetext{
${ }^{57}$ See: Manski; Manski, 2018.

${ }^{58}$ Rachel O’Dwyer writes: "What kinds of subjectivity do we want to algorithmically inscribe into our systems? Blockchain start-ups begin from the assumption that there is no trust and no community, only individual economic agents acting in self-interest. Fair enough, you might think, it's precisely the fact that projects like Ethereum engineer confidence and provides economic incentives for contribution that may distinguish it from other services like Freenet. But it also proceeds from a perspective that already presumes a neoliberal subject and an economic mode of governance in the face of social and/or political problems. 'How do we manage and incentivise individual competitive economic agents?' In doing so, it not only codes for that subject, we might argue that it also reproduces that subject." Sourced from:
} https://www.academia.edu/11627298/The_Revolution_Will_not_be_Decentralised_Blockchainbased_Technologies_and_the_Commons. 
warned, distributed ledgers may end up transactionalizing our entire lives ${ }^{59}$ (scenario 1 and 2 from Manski).

At the very least though, the new distributed capitalism can create more capacities for what Adam Arvidsson (Arvidsson, forthcoming 2019), following Giovanni Arrighi (ARRIGHI, 2009), call 'industrious capitalism' (or rather, 'industrious modernity', as it can also be non-capitalist ${ }^{60}$ ). This is a vision of capitalism and markets seen in the context of a 'class struggle' for markets, whereby workers and a multitude of small firms use market forms to their own benefit, until today mostly in rather invisible informal economies. Distributed capitalism may put these forms on steroids.

The interesting White Paper by Outlier Ventures, a venture capitalist firm founded by Jamie Burke which exclusively invests in 'decentralized infrastructures' is very illustrative on the proposed relationship between open source commons, in the form of blockchains and tokens, and how it fits in a new vision for capitalism. Their paper on Community Token Economies ${ }^{61}$ argues that 'siloed innovation' is inherently wasteful, on the one hand because of its endless duplication in the creation of common infrastructures, but also because, in case of failure, which is the norm rather than the exception, valuable innovation is lost each time the Intellectual Property is lost. Therefore, businesses must massively mutualize their common infrastructures, and community tokens serve to align the various stakeholders, while also providing a funding mechanism for open source developments. While there is a obvious call for more inclusion and fairness in the ecosystem through decentralization, there is no questioning of the primacy of profit maximisation. Thus, blockchain capitalism is indeed a

\footnotetext{
${ }^{59}$ Salvatore Iaconesi writes: "On the one hand, they are a very powerful agent towards the "transactionalization of life", that is of the fact that all the elements of our lives are progressively turning into transactions. Which overlaps with the fact that they become "financialized". Everything, including our relations and emotions, progressively becomes transactionalized/financialized, and the Blockchain represent an apex of this tendency. This is already becoming a problem for informality, for the possibility of transgression, for the normation and normalization of conflicts and, thus, in prospect, for our liberties and fundamental rights, and for our possibility to perceive them (because we are talking about psychological effects). On the other hand, they move attention onto the algorithm, on the system, on the framework. Instead of supporting and maintaining the necessity and culture of establishing co-responsibility between human beings, these systems include "trust" in procedural ways". Source: https://startupsventurecapital.com/the-financialization-of-life-a90fe2cb839f.

${ }^{60}$ Adam Arvidsson writes: "I suggest that the people excluded from an industrial modernity that is declining in importance and attractiveness are driving to make up a new industrious modernity. Like the industrious revolution that pioneered the emergence of a new market society during the European Middle Ages, industrious modernity is marked by labor intensive and capital poor actors that rely to a large extent on common knowledge, resources or technologies and that are driven by endogenous motivations like creativity, impact or selfrealization. Taking this industriousness seriously provides us with a new perspective on the future of digital society, capitalist or not". Sourced from: http://aihr.uva.nl/content/events/events/2018/11/industriousmodernity.html.

${ }^{61}$ See: BURKE, J. et al., 2017.
} 
new form of capitalism, in which the commons are embraced, but also to a large degree instrumentalized.

\section{OUR VISION}

We stand for a different vision.

First, we want to make these distributed networks truly cooperative, much more egalitarian, and sustainable, i.e. we want to:

- $\quad$ Embed different values in the design of the shared ledgers, such as through replacing the blockchain with the holochain;

- $\quad$ Replace the principles of trustlessness with a web of trust, i.e. integrate real human realtionships in trust-scaling technologies ${ }^{62}$;

- $\quad$ Replace smart business contracts ${ }^{63}$ with Ostrom contracts, that reflect the principles that govern the commons, i.e. have smart contracts respect the ethical principles of a sustainable and more socially just economy;

- $\quad$ Replace competitive game incentives, based on purely individual motivation and desire for gain, with cooperative game mechanics;

- Diminish the attraction and rewards of extractive activities by rewarding generative activities, etc.

\footnotetext{
${ }^{62}$ Bitcoin has been called 'trustless' because the system was designed so that nobody has to trust anybody else in order for the system to function, and aims to replace the reliance on 'third parties', to one based on the soundness of the verification algorithms; by contrast, the web of trust is a scaling mechanism for personal trust, following the logic: 'if a trusts $\mathrm{b}$, and b trusts $\mathrm{c}$, than a can also trust c'. In this context, Holochain applies this principle by making context-specific ledgers, where trust exists locally and contextually, interoperable with other ledgers that are similarly trustfull.

${ }^{63}$ See: https://blog.p2pfoundation.net/tag/p2p-models for an explanation of Ostrom contracts.
} 
- INOVAÇÃo

Figure 6 - Contrasting the Propertarian Blockchain from Commons-Based Ledger Systems

\begin{tabular}{|c|c|c|}
\hline \multicolumn{3}{|c|}{ LEDGER PROJECTS: } \\
\hline LIBERTARIAN & vs. & COMMONS-BASED \\
\hline \multicolumn{3}{|l|}{ Examples } \\
\hline Bitcoin, Ethereum, Blockchain & & Holochain, Faircoin, EcSA \\
\hline \multicolumn{3}{|l|}{ Principles: } \\
\hline Commodity-based & & Mutual credit, Contribution-based \\
\hline Tokens and Cryptocurrencies & & and Asset-backed Tokens \\
\hline Competitive Games & & Cooperative Games \\
\hline Smart Contracts & & Ostrom Contracts \\
\hline (individual to individual) & & (social contracts and charters) \\
\hline Oligarchic Proofs of Consensus & & Distributed and Contributory Proofs \\
\hline \multicolumn{3}{|l|}{ (one dollar, one vote) } \\
\hline One World Ledger to Rule them All & & Interoperable P2P Ledger Systems \\
\hline Ethereum & & Holochain \\
\hline Market Value & & Value Sovereignty \\
\hline Extractive Ecosystems & & Generative, Nature-friendly Ecosystems \\
\hline Profit-Driven & & Impact, Purpose, For-benefit Driven \\
\hline Trustless & & Trust-ful (Web of Trust) \\
\hline \multicolumn{3}{|l|}{ LEDGER PROJECTS: } \\
\hline LIBERTARIAN & vs. & COMMONS-BASED \\
\hline \multicolumn{3}{|l|}{ Examples: } \\
\hline Bitcoin, Ethereum, Blockchain & & Holochain, Faircoin, EcSA \\
\hline \multicolumn{3}{|l|}{ Principles: } \\
\hline Commodity-based & & Mutual credit, Contribution-based \\
\hline Tokens and Cryptocurrencies & & and Asset-backed Tokens \\
\hline Competitive Games & & Cooperative Games \\
\hline Smart Contracts & & Ostrom Contracts \\
\hline (individual to individual) & & (social contracts and charters) \\
\hline
\end{tabular}




\begin{tabular}{|l|l|l|}
\hline Oligarchic Proofs of Consensus & & Distributed and Contributory Proofs \\
\hline (one dollar, one vote) & & \\
\hline One World Ledger to Rule them All & & Interoperable P2P Ledger Systems \\
\hline Ethereum & & Holochain \\
\hline Market Value & & \\
\hline & & Value Sovereignty \\
\hline Extractive Ecosystems & & \\
\hline & & Generative, Nature-friendly Ecosystems \\
\hline Profit-Driven & & \\
\hline & & Impact, Purpose, For-benefit Driven \\
\hline Trustless & & \\
\hline
\end{tabular}

Our proposals reflect the conviction that we can tweak and transform the general idea of the distributed ledger, to make it into a set of tools for production for the common good. More importantly, even if we also want to use distributed ledgers, the aim of their use is to recognize all contributions to the common good and specific projects, not just commercial value recognized by the capitalist market, and we want to recognize these and make them visible. Just as importantly we aim to integrate the limits necessary to preserve our planet and its multitude of beings for a long time, including a future for our children and the next generations by making visible, in our distributed accounting systems, the thermo-dynamic flows of matter and energy, creating a context-based sustainability framework ${ }^{64}$ for all participants in these networks.

Automating some of these functions may help managing them. Expanding our capacity to integrate commons-based, permissionless and passionate contributions in our productive system, however, is equally important. Even as we want to create ethical and generative livelihoods for all contributions, this does not mean necessarily directly linking commons activities to market income. As we explained above, the solution is to create a membrane which regulates the relation between market and commons. This is of supreme importance if we want to avoid a hyper-rationalisation of our behaviour and avoid a transactionalisation of all aspects of life. We don't want to subsume the commons to the market and its logic, but to embed and subsume the market to the necessities of human and

\footnotetext{
${ }^{64}$ See also: https://wiki.p2pfoundation.net/Sustainability_Context.
} 
non-human commons. By automating some of the aspects of human cooperation, we want to create more space for non-market commoning.

And thus, despite these limitations, and our critique of the current blockchain, the qualities and advantages that the blockchain has brought into the world are of paramount importance. What matters is not just the flawed technology, but the patterns of thought and interaction that it makes possible.

- First of all, it has enabled the flow and exchange of crypto-assets and forms of value, outside of the control of the existing and centralized financial system. It is now possible to finance open source network infrastructures, in ways that go beyond the prior dependency on the banking, payment, and financial and venture capital based entities;

- This enabled a different line of thought on value and money. Alternative value systems can be embedded in currencies, as money is a social construct: imagined and designed by humans. While local complementary currencies have shown the potential for creating local solutions, the new systems show that socially sovereign currencies are scalable, and can be used by global virtual communities;

- Blockchain economies subsume bounded firms to the logic of the network, based on the use of open source commons and autonomously created monetary tools. Corporations become co-dependent on multi-stakeholder networks and commons;

- Token-based blockchain economies have the potential to shift the balance of power between labor and capital. They may allow a bigger part of the surplus value to flow to workers and other stakeholders, avoiding domination by venture capital demand for an equity stake;

The question is: will these techniques, which favour a particular fraction of the labour aristocracy of developers and technical-cognitive labour, also be applied for the wider commons economy? Our position here is positive: all commoners can and must learn about how this has been achieved, and whether it can be properly replicated elsewhere.

The specific design used in the creation of tokens is also paramount. Tokens allow for the expression of multiple forms of value, which can eventually allow for the value sovereignty we call for. The issuing of tokens for use as a medium of exchange / store of value within communities can be done in a way that incentivises preferred behaviours and reinforces preferred values That is creating a direct break of the dominant perception of money as commodity and opens up the possibilities for other types of perceptions of value.

Most importantly, blockchains enable and ascribe the general consensus on such subjective perceptions among communities, while facilitating the interaction among them. Simply put, when a group of people agree that a certain activity has merit, they can create a permanent and tamper-proof record of this agreement. Let's imagine for instance an energy 
cooperative building small-scale wind-turbine. Its members may collaborate and create a set of rules for the issue of tokens to engage more people in their cause (e.g. energy engineers, households that want to reduce their dependence on fossil fuel, etc.), and interact with other groups that may provide resources or support services (e.g. a group of smart-grid experts, an impact finance firm, etc.).

Moreover, crypto-tokens allow for crowdfunding or direct crowdsales, either through utility tokens (a right to purchase the assets created by a blockchain project) or through market-based tokens which allows stakeholders to partage in the surplus value realized in the market. This allows founders, developers and workers to go around the centralized banking and venture capital system, finding their own funding more directly. These crowdfunding campaigns, based on the sale of tokens that are open to all types of buyers, are called Initial Coin Offerings.

Speculative 'Initial Coin Offerings', can also be initial community offerings, as in the crowdfunding campaign by Holochain. If the crowdfunding is successful, projects can go ahead outside of the control of Venture Capital, which expects equity, i.e. co-ownership, in return for its investments. By contrast tokens and Initial Token Offerings, allows for the direct funding the workers, developers and other stakeholders. If the project is successful and the token-price moves upward, the work-related tokens rise in value, directly benefiting the workers, who partake in the surplus value that was previously captured by the funders.

As Fred Ehrsam (2016), of Coinbase expressed it:

So how do you get people to join a brand-new network? You give people partial ownership of the network. Just like equity in a startup, it is more valuable to join the network early because you get more ownership. Decentralized applications do this by paying their contributors in their token. And there is potential for that token (partial ownership of the network) to be worth more in the future.

We believe that the organization of a crypto-economy for the common good, based on enabling commons-based peer production, which combines a recognition of a wider variety of contributions, and helps achieve biocapacity accountability, will be based on:

1. a better integration of free and cooperative mutual coordination, exchange and,

2. the mobilization of resources through a fair and generative ethical market, and,

3. within a planning framework that reflects a protection of planetary boundaries, and regulates access to the flows of matter-energy to determine the bounds of usage through thresholds and allocations of natural resources, as well as societal priorities. 
Box 5 - Alternatives Distributed Ledger Technologies

\begin{tabular}{|l|l|l|l|}
\hline Technology & \multicolumn{1}{|c|}{ Description } & \multicolumn{1}{c|}{ Applications } & \multicolumn{1}{c|}{$\begin{array}{c}\text { Characteristics/ } \\
\text { Advantages }\end{array}$} \\
\hline Tangle & $\begin{array}{l}\text { A network data structure } \\
\text { designed to facilitate a } \\
\text { range of secure } \\
\text { transactions. To carry out a } \\
\text { transaction you need to } \\
\text { validate two random } \\
\text { previous ones. }\end{array}$ & $\begin{array}{l}\text { IOTA: resource } \\
\text { sharing platform for } \\
\text { Internet of Things } \\
\text { devices }\end{array}$ & $\begin{array}{l}\text { + no miners, no transaction } \\
\text { fees } \\
\text { + consensus mechanism } \\
\text { embedded in transactions } \\
\text { + faster with more users } \\
\text { + focused on machine-to- } \\
\text { machine communication }\end{array}$ \\
\hline
\end{tabular}


ARVIDSSON, A. Industrious modernity: On the future of digital capitalism. Available at: http://www.spui25.nl/spui25-en/events/events/2018/11/industrious-modernity-on-the-futureof-digital-capitalism.html. access in: 05 dez. 2018.

ARRIGHI, G. Adam Smith in Beijing: Lineages of the 21st Century. London: Verso, 2009.

BARBROOK, R.; CAMERON, A. The Internet Revolution: From Dot-com Capitalism to Cybernetic Communism. Amsterdam: Institute for Network Cultures, 2016. Available at: http://networkcultures.org/wp-content/uploads/2015/10/0585-INC_NN10-totaal-RGB.pdf. Access in: 05 jan. 2018.

BARBROOK, R. Cyber-Communism: How the Americans are Superseding Capitalism in Cyberspace. Science as Culture, v. 9, n. 1, p. 5-40, 2000.

BAUWENS, M.; NIAROS, V. Value in the Commons. Berlin: Amsterdam: Heinrich Böll; P2P Foundation, 2017a. Available at: http://commonstransition.org/value-commonseconomy/. Access in: 05 jan. 2018.

BAUWENS, M.; NIAROS, V. Changing Societies Through Urban Commons Transitions. Berlin: Heinrich Böll Foundation, 2017b. Available at:

http://commonstransition.org/changing-societies-through-urban-commons-transitions. Access in: 12 jan. 2018.

BAUWENS, M.; NIAROS, V. Changing Societies Through Urban Commons Transitions. Amsterdam: P2P Foundation, 2016.

BAUWENS, M.; KOSTAKIS, V. From the Communism of Capital to Capital for the Commons: Towards an Open Co-operativism. Triple C, v. 12, n. 1, p. 356-361, 2014. Available at: http://www.triple-c.at/index.php/tripleC/article/view/561. Access in: 05 jan. 2018.

BENKLER, Y. The Penguin and the Leviathan: How Cooperation Triumphs over SelfInterest. Yardley, PA: Crown, 2011.

BENKLER, Y. The Wealth of Networks: How Social Production Transforms Markets and Freedom. New Haven, CT: Yale University Press, 2006.

BOCKMAN, J.; FISCHER, A.; WOODRUFF, D. Socialist Accounting by Karl Polanyi: with preface "Socialism and the embedded economy". Theory and Society, v. 45, n. 5, p. 385427, 2016.

BOTERO, G. Delle Cause della Grandezza delle Cittá: A cura di Romain Descendre. Collana: Cliopoli, 5, 2016.

BURKE, J. et al. Community Token Economies (CTE): Creating sustainable digital token economies within open source communities. Amsterdam: P2P foundation; Outlier Ventures, September 2017. Available at:

https://gallery.mailchimp.com/65ae955d98e06dbd6fc737bf7/files/02455450-8a66-4004-965acf2f19fed237/Community_Token_Economy_Whitepaper_1.0.1_2017_09_01.pdf. 
DAFERMOS, G. The Catalan Integral Cooperative: An Organizational Study of a Postcapitalist Cooperative. Amsterdam: P2P Foundation; Robin Hood Coop, 2017. Available at: https://p2pfoundation.net/wp-content/uploads/2017/10/The-Catalan-Integral-Cooperative.pdf. Access in: 12 jan. 2018.

DARDOT, P.; LAVAL, C. Commun: essai sur la revolution au XXIème siècle. Paris: La Decouverte, 2014.

DE ANGELIS, M. Omnia Sunt Communia: on the Commons and the Transformation to Postcapitalism. London: Zed Books, 2017.

DUNN, C., GERARD, G. J.; GRABSKI, S. V. Resources-Events-Agents Design Theory: A Revolutionary Approach to Enterprise System Design. Communications of the Association for Information Systems, v. 38, 2016.

ECONOMIC SPACE AGENCY. On Intensive Self-Issuance: Economic Space Agency and the Space Platform. In: GLOERICH, I.; LOVINK, G.; VRIES, P. (eds.) Moneylab Reader 2: Overcoming the Hype, Institute of Network Cultures. 2018. p. 232-242.

EHRSAM, F. Blockchain Tokens and the dawn of the Decentralized Business Model. In: The Coinbase Blog. [S. l.], Aug 1, 2016. Available at: https://blog.coinbase.com/app-coinsand-the-dawn-of-the-decentralized-business-model-8b8c951e734f. Access in: 14 jan. 2018.

EKBIA, H. R.; NARDI, B. A. Heteromation, and Other Stories of Computing and Capitalism. Cambridge, MA: MIT Press, 2017.

ELKINGTON, J. Towards the Sustainable Corporation: Win-Win-Win Business Strategies for Sustainable Development. California Management Review, v. 36, n. 2, p. 90-100, 1994.

FERNÁNDEZ, R. V. The pattern of socio-ecological systems: a focus on energy, human activity, value added and material products. Thesis (Doctoral). 2017. [Barcelona]: Universitat Autònoma de Barcelona, 2017. Available at: https://ddd.uab.cat/record/187290?ln=en. Access in: 05 jan. 2018.

FOTI, A. General Theory of the Precariat: Great Recession, Revolution, Reaction. Amsterdam: Institute of Network Cultures, 2017.

FUGGER, R. Money as IOUs in Social Trust Networks \& A Proposal for a Decentralized Currency Network Protocol. April 18, 2004. Available at: http://archive.rippleproject.org/decentralizedcurrency.pdf. Access in: 05 jan. 2018.

GIAMPIETRO, M.; MAYUMI, K. Multiple-Scale Integrated Assessment of Societal Metabolism: Introducing the Approach. Population and the Environment, v. 22, n. 2, p. 109-153, 2000.

GLEESON-WHITE, J. Double Entry: How the Merchants of Venice Created Modern Finance. New York: W.W. Norton \& Company, 2013.

HAUGEN, R.; MCCARTHY, W. EREA: A semantic model for internet supply chain collaboration. ACM CONFERENCE ON OBJECT-ORIENTED PROGRAMMING, SYSTEMS, LANGUAGES, AND APPLICATIONS, 21, January 2000, Minneapolis. 
Available at:

http://jeffsutherland.org/oopsla2000/mccarthy/mccarthy.htm. Access in: 10 jan. 2018.

KELLY, M. Owning Our Future: The Emerging Ownership Revolution - Journeys to a Generative Economy. Oakland, CA: Berrett-Koehler Publishers, 2012.

KOSTAKIS et al. 2015. Design Global, Manufacture Local: Exploring the Contours of an Emerging Productive Model. Futures, v. 73, p. 126-135. Available at: http://www.p2plab.gr/el/wp-content/uploads/2015/09/Futures.pdf. Access in: 10 jan. 2018.

LE GOFF, J. La naissance du Purgatoire. Paris: Gallimard, 1981.

MANSKI, S.; MANSKI, B. No Gods, No Masters, No Coders? The Future of Sovereignty in a Blockchain World. Law Critique, v. 29, p. 151-162, 2018.

MARSH, L.; ONOF, C. Stigmergic Epistemology, Stigmergic Cognition. Cognitive Systems Research, v. 9, n. 1-2, p. 136-149, 2007.

MCCARTHY, W. E. Construction and use of integrated accounting systems with entityrelationship modeling. In: CHEN, P. (ed.) Entity-relationship approach to systems analysis and design. Amsterdam: North Holland Publishing Company, 1980. p. 625-637.

MCCARTHY, W. E. The REA accounting model: A generalized framework for accounting systems in a shared data environment. The Accounting Review, v. 57, n. 3, p. 554-578, 1982.

MOTESHARREI, S.; RIVAS, J.; KALNAY, E. Human and nature dynamics (HANDY): Modeling inequality and use of resources in the collapse or sustainability of societies. Ecological Economics, v. 101, p. 90-102, 2014.

PAZAITIS, A.; DE FILIPPI, P.; KOSTAKIS, V. Blockchain and value systems in the sharing economy: The illustrative case of Backfeed. Technological Forecasting \& Social Change, v. 125 , p. 105-115, 2017 a.

PEREZ, C. Technological Revolutions and Financial Capital: The Dynamics of Bubbles and Golden Ages. Cheltenham: Edward Elgar Pub. 2002.

POLANYI, K. The Great Transformation: The Political and Economic Origins of our Time. Boston: Beacon Press, 1957.

PORTER, M. E. Location, Competition, and Economic Development: Local Clusters in a Global Economy. Economic Development Quarterly, v. 14, n. 1, p. 15-34, 2000.

PORTER, M. E. The Competitive Advantage of Nations. New York: Free Press. 1990.

RAMOS, J. Cosmo-localization and leadership for the future. Journal of Futures Studies, v. 21, n. 4, p. 65-84, 2017.

RAWORTH, K. The Doughnut Economics: 7 Ways to Think Like a 21st Century Economist. Harford, VT: Chelsea Green Publishing, 2018. 
SANGSTER, A. Using accounting history and Luca Pacioli to put relevance back into the teaching of double entry. Accounting, Business \& Financial History, v. 20, 1, p. 23-39, 2010 .

SOMBART, W. Der Moderne Kapitalismus, Bd. 1: Die Genesis des Kapitalismus. Leipzig: Duncker \& Humbolt, 1902.

SPUFFORD, P. Power and Profit: The Merchant in Medieval Europe. London: Thames \& Hudson, 2002.

STANDING, G. The Precariat: The new dangerous class. Broadway: Bloomsbury Academic, 2011.

TEECE, D. Competition, cooperation and innovation: organisational arrangements for regimes of rapid technological progress. Journal of Economic Behaviour and Organisation, v. 18, n. 1, p. 1-25, 1992.

VANDENBOSSCHE, P. E. A.; WORTMANN, J. C. Why accounting data models from research are not incorporated in ERP systems. INTERNATIONAL REA TECHNOLOGY WORKSHOP, 2., 25 June, Santorini Island, 2006. p. 4-30.

WHITAKER, M. D. Ecological Revolution: The Political Origins of Environmental Degradation and the Environmental Origins of Axial Religions; China, Japan, Europe. Available at:

https://wiki.p2pfoundation.net/Political_Origins_of_Environmental_Degradation_and_the_En vironmental_Origins_of_Axial_Religions. Access In: 05 jan. 2018. 